\title{
Correspondence
}

\section{The views of voluntary patients}

Sir: We read with interest Paul \& Oyebode's paper regarding the competence of voluntary psychiatric patients (Psychiatric Bulletin, August $1999,463-466)$. We too have data on a related, but distinct, area of research. One hundred consecutive informal patients were interviewed on the third day of admission and one week later. At the first assessment, 78\% thought they needed to be in hospital and 74\% thought they needed treatment. Only $43 \%$ recalled receiving an explanation of their admission and treatment plan. We assessed their knowledge of their rights to refuse admission and treatment. At the first assessment, $67 \%$ were aware of their right to refuse treatment with $52 \%$ anticipating coercion if they exercised this right. Seventy-three per cent were aware of their right to leave hospital an $42 \%$ anticipated coercion if they exercised this right.

A modified information leaflet (Sugarman \& Long, 1992), explaining their rights as voluntary patients was administered. At reassessment, $78 \%$ were aware of their right to refuse treatment and $29 \%$ anticipated coercion on exercising this right. Ninety-one per cent were aware of their right to leave hospital with $22 \%$ anticipating coercion if so doing. These changes were statistically significant at $P<0.001$ and $P<0.005$ respectively. Sixty-one per cent could remember receiving information about their treatment and hospital stay.

The first stage of this study revealed a minority of patients recalling information regarding their treatment. It may be that either that this information had not been given or that it was difficult to recall. Surprisingly the majority indicated that they agreed with the need for hospitalisation and treatment. This is in spite of the majority of patients not recollecting having been given an explanation of the treatment plan. As in Paul \& Oyebode's article it appears that other factors account for consent to be given, for example, trust in the doctors, subjective distress and an incorrect view of the situation and its consequences. Our results show that the use of the information leaflet for this group of patients could be helpful in enabling them to consider the options open to them. This would then aid the process of obtaining informed consent.

\section{References}

SugARMAN, P. \& LONG, A. (1992) Informing voluntary patients of their rights. Psychiatric Bulletin, 16, 1477.
* Julia Moss, Senior Registrar in Child and Adolescent Psychiatry, South Warwickshire Combined Care Trust, Orchard House, 83 Radford Road, Leamington Spa, Warwickshire; Anne Doyle, Senior Registrar in General Adult Psychiatry, Queen Elizabeth Psychiatric Hospital Edgbaston, Birmingham; Andrew Macdonald, Consultant Psychiatrist, Wakefield and Pontefract Community Health Trust; and Ajaya Upadhaya, Senior Instructor, Department of Psychiatry, University of Rochester, Rochester, New York, USA

*Correspondence

\section{The Internet and its actual influence on suicide}

Sir: Thompson's review (Psychiatric Bulletin, August 1999, 23, 449-451) of the Internet and its influence on suicide includes a discussion of Haut \& Morrison's (1998) report detailing websites which describe methods of suicide. We wish to report the perhaps inevitable next stage in the Internet's potential for facilitating suicide attempts: that of a case in which medication was bought through the Internet and then used in a suicide attempt.

The patient is a 40-year-old man who has been attending an addiction unit with alcohol dependence syndrome. He took an overdose of phenytoin and chlordiazepoxide. At interview after discharge from hospital he said he had purchased the medication from the Internet for selfdetoxication.

On investigation of the Website the company offers a wide range of medication including antidepressants, benzodiazepines, opiates (buprenorphine oral and ampoules) and insulin. Insurance can be paid against customs seizure and advice is given about avoiding detection, for example, the use of varying delivery names and addresses.

With information readily available about methods of suicide psychiatrists should be aware that their patients may also have access to potentially lethal medication. There are of course implications for the addiction field.

We are sure that this will not be the first case of its kind but believe that the more this is reported the more pressure will be exerted on regulators. 


\section{References}

HAUT, \& MORRISON, A. (1998) The Internet and the future of psychiatry. Psychiatric Bulletin, 22, 641-642.

Jo Banbery, Associate Specialist, David West, Head of Information, Leeds Addiction Unit, 19 Springfield Mount, Leeds, West Yorkshire LS2 9NG

\section{Increasing the cross-fertilisation of ideas between training schemes}

Sir: I have had the opportunity, as the specialist registrar representative on a Child and Adolescent Psychiatric Special Advisory Sub-Committee team, to visit a different child and adolescent training scheme than my own. This was a very interesting experience both with regard to the process of the visit and seeing how another scheme functions. It also exposed me to new ideas about training. I strongly support the view expressed by Laurence Sheldon (1994) that approval visits should be open for any interested specialist registrar and recommend other trainees to consider offering themselves for approval visits.

Further food for thought has come from the biannual joint meetings that the scheme I am on has with a neighbouring scheme. One cannot help but compare one's own scheme and others. Clearly all have strengths and weaknesses and this is discussed among trainees and trainers. Such encounters can be a stimulus for the reappraisal and development of training schemes.

Schemes will vary according to size, historical context, geography and mix of personalities. Individual training schemes develop particular approaches to problems, using the locally available resources and so will be different. Nevertheless, it is highly likely that some problems will be widespread across many schemes. I would therefore advocate that the cross-fertilisation process between schemes is a significant way of continually improving the training offered.

\section{References}

Sheldon, L. (1994) Use of approval visits by the CTC. Psychiatric Bulletin, 18, 506.

David White, Specialist Registrar, Child and Adolescent Service, Fieldhead House, 2-8 St Martin's Avenue, Listerhills, Bradford BD7 1LG

Usage of clozapine and new neuroleptics

Sir: Bristow (Psychiatric Bulletin, August 1999, 23, 478-480) found $9.5 \%$ of psychiatrists said their trust restricted clozapine funding. By contrast, the Maudsley National Schizophrenia Fellowship (1998) survey of health authority pharmaceutical advisors reported in the Pharmaceutical Journal found clozapine funding restricted by $45 \%$ of health authorities. We have recently carried out a postal questionnaire of members of the UK Psychiatric Pharmacists Group on the use and evaluation of atypical antipsychotics. We received 82 replies giving a response rate of $45 \%$. Eleven per cent of pharmacists reported their trust capped the number of patients prescribed clozapine. However, there was widespread use of measures by trusts to try and limit expenditure on atypicals, restricting the prescribing of atypicals to consultants only and the use of guidelines in which atypicals are not first line treatment for schizophrenia. Only $12 \%$ of trusts, our hospital among them, used no cost-containment measures.

\section{References}

MaUdSLEy National Schizophrenia Fellowship (1998) Are patients with schizophrenia denied the best treatment? Pharmaceutical Journal, 281, 847.

Camilla Haw, Consultant Psychiatrist, Jean Stubbs, Head of Pharmacy, St. Andrew's Hospital, Billing Road, Northampton NN1 5DG

\section{The law and suicide}

Sir: Thompson (Psychiatric Bulletin, August 1999, 23, 449-451), states the Suicide Act of 1961 prohibits others from encouraging suicide', and concludes that there may, therefore, exist 'legal grounds' sanctioning suicide Websites. These suggested measures include possibly tracing vulnerable individuals' who have disclosed suicidal thoughts, or who have communicated, for example, by way of the site bulletin board, that they have just acted on their suicidal ideation. Yet, it is difficult to see how there could be legal grounds propelling health care professionals (presumably), or any other individual, into such interventions. The Suicide Act 1961, prohibits the aiding and abetting' of suicide, but this is not necessarily synonymous with merely 'encouraging' suicide per se. Criminal liability arises in circumstances where a person takes active steps in assisting the suicide of another, such as by telling someone the amount of a drug required to secure death and leaving this within their reach. The Suicide Act 1961 does not extend to Scotland, although any individual taking similarly unambiguous steps to assist another in suicide might face 'art and part' liability in the aiding and abetting of a suicide, possibly resulting in a charge of culpable homicide. Neither does it apply to other countries, and it must be borne in mind that assistance in suicide is not a crime everywhere. Therefore, there can exist no competent application of the 